\title{
An Unusual Case of Palpitations: Pectus Excavatum
}

\author{
Zulfiqar Ali Sandhu ${ }^{1 *}$, Sharjeel Shaikh ${ }^{2}$ and Aidan Buckley ${ }^{3}$ \\ ${ }^{1}$ AMAU Staff Physician, Wexford General Hospital, Ireland \\ ${ }^{2}$ Staff Physician, General Medicine, Wexford General Hospital, Ireland \\ ${ }^{3}$ Consultant Cardiologist, Wexford General Hospital, Ireland
}

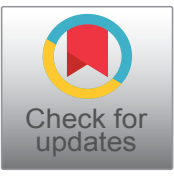

*Corresponding author: Zulfiqar Ali Sandhu, AMAU Staff Physician, Wexford General Hospital, Ireland

\section{Case Report}

We recently encountered a 67-year-old lady who was sent by her GP to our Acute Medical Assessment Unit with complains of palpitations. These were significantly affecting her day to day activities. She described the palpitations as a 'thumping' sensation in the chest with 'skipping beats' without any associated shortness of breath, pre syncope or collapse. The symptoms were prominent at lying flat very short lived and the number of events increased over time.

Further evaluation revealed that she was a lifelong non smoker, with hypertension and hypothyroidism. She used as medication Acerycal 10/10 and Eltroxin 100 mcg OD. She was clinically and biochemically euthyroid. Her CVS exam was unremarkable. Her ECG showed frequent supra ventricular ectopics with $P$ wave inversion in V1. The Transthoracic Echocardiogram revealed a structurally and functionally normal heart.

Holter monitor showed sinus rhythm with bundle branch pattern with frequent supraventricular and AV junctional ectopics. The burden of ectopics was 11,124 in 24 hrs. She had a Cardiac MRI performed which showed a modest pectus excavatum and no myocardial abnormality. The pectus focally ran in close proximity to $\mathrm{RV}$ wall at mid ventricular level.

Her symptoms were likely secondary to local irritant effect of the pectus on RV free wall during periods of RV filling.

She was subsequently commenced on a low dose Bisoprolol as Ectopic suppressant. A repeat Holter monitor showed sinus rhythym throughout with very rare
PACs. She had significant symptomatic relief and is currently doing well on Bisoprolol.

\section{Discussion}

Pectus excavatum is a congenital deformation of the chest, presenting as a funnel-shaped impression in the median frontal chest between the fourth and the seventh rib. Asymmetric presentation occurs, and the extent of deformation may vary from slight to serious. Exact numbers about prevalence are difficult to obtain, as the deformation is often not noted or-when noted-is not mentioned in the medical reports. Pectus excavatum is found in Europe in at least one in every 1000 births, mainly in men (70-85\%) and often within the same families (35-45\%). A correlation is mentioned between pectus excavatum and relatively rare syndromes as Ehlers Danlos, Marfan syndrome, or Poland syndrome [1-5]. Mitral valve prolapse occurs in $15 \%$ of patients with pectus excavatum $[1,6]$. In severe forms of pectus excavatum, the inward deformation of the sternum creates an impression on the right atrium or ventricle. This can cause cardiac compression $[1,6,7]$ (Figure 1 and Figure 2).

Cardiac manifestations result from the posterior displacement of the sternum, producing an anterior indentation and deformity of the right ventricle. In severe cases, the heart may become rotationally displaced into the left hemi thorax. This displacement can cause mechanical compression and obstruction to normal outflow which may impede normal stroke volume, especially during exercise. This diminished cardiac stroke volume has been well established, especially in a seated or upright position. Of note, 


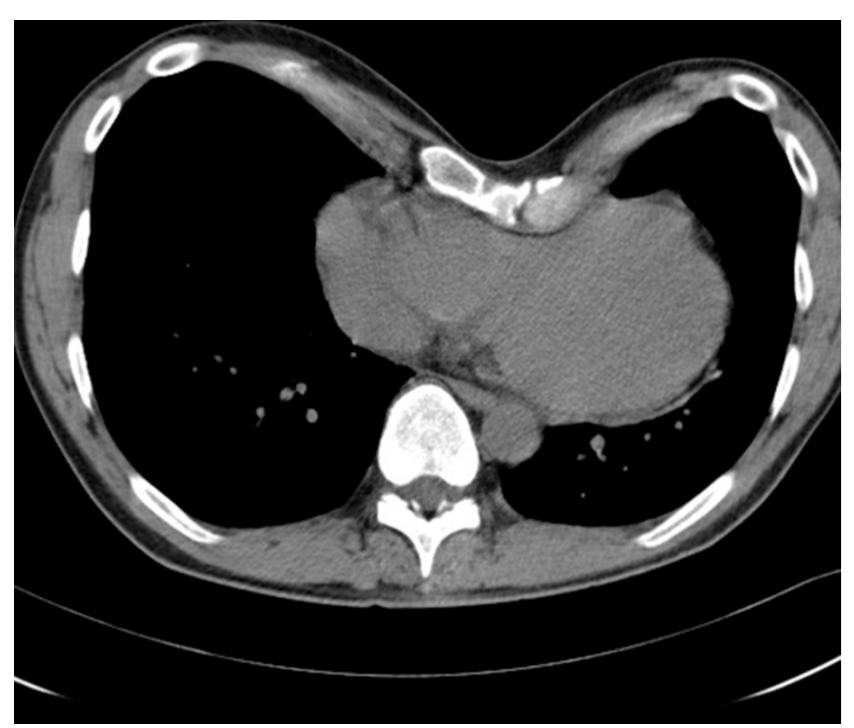

Figure 1: Transversal CT of the chest.

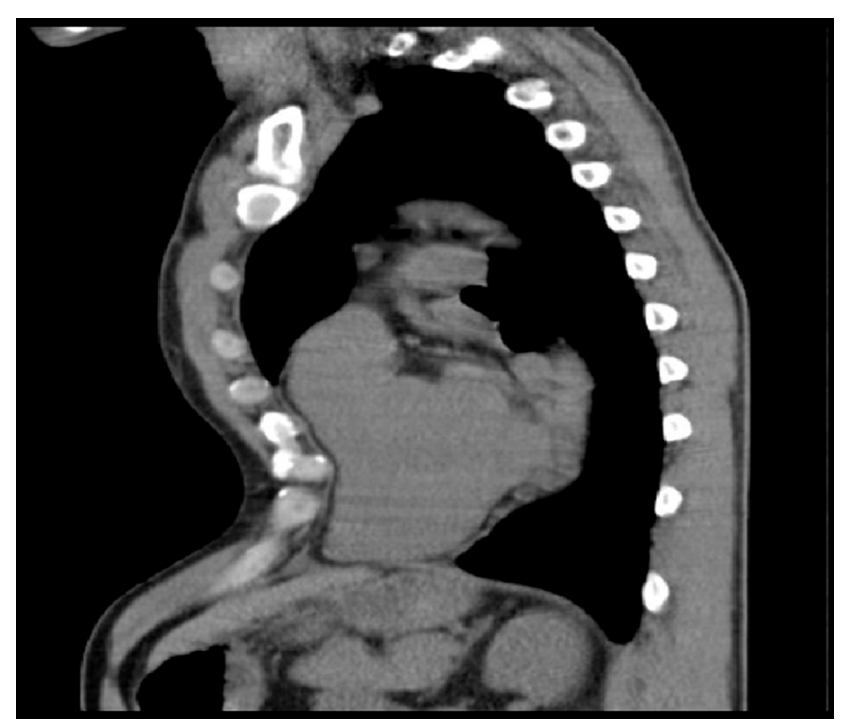

Figure 2: Sagittal CT of the chest.

stroke volume tends to normalize while supine.

Valvular abnormalities are common among patients with pectus excavatum, particularly mitral valve prolapse. Mitral valve prolapse is thought to result from deformities of the mitral annulus produced by anterior compression of the heart. It occurs in $20 \%$ of patients with pectus excavatum. Resolution occurs in over $50 \%$ of individuals following corrective surgery [5]. In one series, systolic murmurs were auscultated in $46 \%$ of cases not associated with an underlying connective tissue disorder [4]. The prevalence of murmurs was independent of the degree of deformity in this study.

The change in cardiac position caused by the thoracic deformity in this patients with pectus excavatum produced a more or less constant characteristic electrocardiographic findings, which, although not pathognomonic, can be suggestive of this anomaly. These findings are: a) S1S3 or S1Q3; b) negative $P$ waves in $\mathrm{VI}$; and C) qr or rsr' in $\mathrm{VI}$ [8].

Pectus excavatum is an uncommon cause of Cardiac Arrhythmias and Rhythm Disturbance in a structurally normal heart.

\section{References}

1. Fonkalsrud EW (2009) 912 Open pectus excavatum repairs. Changing trends, lessons learned. One surgeon's experience. World J Surg 33: 180-190.

2. Goretsky MJ, Kelly RE, Croitoru D, Nuss D (2004) Chest wall anomalies. Pectus excavatum and pectus carinatum. Adolesc Med 15: 455-471.

3. Kelly RE, Shamberger RC, Mellins RB, Mitchell KK, Lawson ML, et al. (2007) Prospective multicenter study of surgical correction of pectus excavatum: Design, perioperative complications, pain, and baseline pulmonary function. Facilitated by internet-based data collection. J Am Coll Surg 205: 205-216.

4. Creswick HA, Stacey W, Kelly RE, Gustin T, Nuss D, et al. (2006) Family study of the inheritance of pectus excavatum. J Pediatr Surg 41: 1699-1703.

5. Crump HW (1992) Pectus excavatum-pathophysiology, clinical presentation, surgical repair. Am Fam Physician 46: 173-179.

6. Malek MH, Berger DE, Housh TJ, Marelich WD, Coburn JW, et al. (2006) Cardiovascular function following surgical repair of pectus excavatum: A metaanalysis. Chest 130: 506-515.

7. Robicsek F, Watts LT, Fokin AA (2009) Surgical repair of pectus excavatum and carinatum. Semin Thorac Cardiovasc Surg 21: 64-75.

8. Martins De Oliveira J, Sambhi MP, Zimmerman HA (1957) The electrocardiogram in pectus excavatum. Br Heart J 12: 495-501. 